\title{
End stage and chronic kidney disease: associations with renal cancer
}

\author{
Paul Russo ${ }^{1,2}$ * \\ ${ }^{1}$ Department of Surgery, Urology Service, Memorial Sloan Kettering Cancer Center, New York, NY, USA \\ ${ }^{2}$ Memorial Sloan Kettering Cancer Center, Weill Medical College, Cornell University, New York, NY, USA
}

\section{Edited by:}

Bin Tean Teh, Van Andel Research Institute, USA

\section{Reviewed by:}

Min-Han Tan, Institute of

Bioengineering and Nanotechnology, Singapore

Tsung Wen Chong, Singapore General Hospital, Singapore

\section{*Correspondence}

Paul Russo, Department of Surgery, Urology Service, Memorial Sloan Kettering Cancer Center, 1275 York Avenue, NY 10021, USA.

e-mail: russop@mskcc.org
There is a well known association between end stage renal disease and the development of kidney cancer in the native kidney of patients requiring renal replacement therapy. There is now emerging evidence that lesser degrees of renal insufficiency (chronic kidney disease, CKD) are also associated with an increased likelihood of cancer in general and kidney cancer in particular. Nephropathological changes are commonly observed in the non-tumor bearing portions of kidney resected at the time of partial and radical nephrectomy (RN). In addition, patients with renal cancer are more likely to have CKD at the time of diagnosis and treatment than the general population. The exact mechanism by which renal insufficiency transforms normal kidney cells into tumor cells is not known. Possible mechanisms include uremic immune inhibition or increased exposure to circulating toxins not adequately cleared by the kidneys. Surgeons managing kidney tumors must have an increased awareness of their patient's renal functional status as they plan their resection. Kidney sparing approaches, including partial nephrectomy (PN) or active surveillance in older and morbidly ill patients, can prevent CKD or delay the further decline in renal function which is well documented with RN. Despite emerging evidence that PN provides equivalent local tumor control to $\mathrm{RN}$ while at the same time preventing CKD, this operation remains under utilized in the United States and abroad. Increased awareness of the bi directional relationship between kidney function and kidney cancer is essential in the contemporary management of kidney cancer.

Keywords: kidney cancer, renal insufficiency, radical nephrectomy, partial nephrectomy, chronic kidney disease

\section{INTRODUCTION}

It is well known that end stage renal disease (ESRD) patients requiring renal replacement therapy either by dialysis or transplantation are at increased risk for developing cancer and at four to fivefold increased risk of developing renal cancer in their native kidneys (Birkelan et al., 2000; Buell et al., 2005; Mandayam and Shahinian, 2008). Mortality related to ESRD related kidney cancer depends upon the variable metastatic potentials of the tumor and competing threats posed by complex cardiovascular and medical diseases which result from or cause of the kidney disease. Emerging evidence now exists which also associates chronic kidney disease (CKD) with a greater risk of cancer and kidney cancer in particular. Diffuse nephropathological changes are commonly observed in the non-neoplastic kidney at the time of nephrectomy for cancer. These histopathological findings correlate with a greater baseline risk of CKD in the kidney patient than the population at large. It is not currently known whether the underlying damage to the kidney is a carcinogenic event in and of itself or whether renal dysfunction allows for carcinogenic toxins or immune inhibition that then transforms normal kidney cells into cancer cells.

For surgeons planning operations on patients with renal tumors, oncological goals of providing local tumor control by radical or partial nephrectomy (PN) must now be tempered by an understanding of the baseline renal functional health of the patient and the potential impact of operation on overall renal function. There is now abundant clinical evidence which suggests radical nephrectomy $(\mathrm{RN})$ for small renal masses is over treatment from an oncological perspective and causes or worsens pre-existing CKD. Knowledge of this bi directional relationship between kidney function and kidney cancer is an essential component in the management of kidney tumor patients.

\section{THE PROBLEM OF KIDNEY CANCER}

An estimated 60,920 new cases and 13,120 deaths from kidney cancer occurred in the United States in 2011. Kidney cancer is increasing at a rate of approximately $3 \%$ per year. Compared with 1971, this represents a fivefold increase in incidence and twofold increase in mortality. Associated risk factors include hypertension, smoking, obesity, and diabetes. Epidemiologic evidence suggests an increase in all stages of renal cancer including the advanced and metastatic cases (McLaughlin and Lipworth, 2000; Ljungberg et al., 2011). Approximately $30-40 \%$ of renal tumor patients will either present with or later develop metastatic disease. The widespread use of the modern abdominal imaging techniques (CT, MRI, and ultrasound) over the last 20 years, usually ordered to evaluate non-specific abdominal and musculoskeletal complaints or during unrelated cancer care, has changed the profile of the typical renal tumor patient from one with a massive, symptomatic tumor at presentation to one with a small, asymptomatic, renal mass $(<4 \mathrm{~cm})$ incidentally discovered in $70 \%$ of the cases (Russo, 
2000). Over the last four decades, evidence from the SEER database suggests an increase in the incidence of kidney cancer in blacks, an American population less likely to have access to incidental tumor detection and exposed to lesser rates of nephrectomy but more likely to have unrecognized and untreated hypertension, diabetes, and CKD. Despite this, mortality rates in blacks are equivalent to whites raising the possibility that kidney cancer is less aggressive in black patients (Lipworth et al., 2011).

Despite this size and stage migration, kidney cancer specific survival rates have not significantly improved over the last 15 years. This disconnect suggests that aggressive treatment of smaller tumors is not sufficient to offset more virulent disease seen in all stages in general or advanced stages in particular (Russo et al., 2008). A survival rate of $90 \%$ or greater, depending on the tumor histology, is expected for small tumors whether PN or RN is performed (Kattan et al., 2001; Russo, 2010). We now understand that renal cortical tumors are members of a complex family with unique histopathology, cytogenetics, familial and hereditary syndromes, and variable metastatic potentials. Approximately 20\% of patients with surgically resected renal masses will be a benign lesion (i.e., angiomyolipoma, oncocytoma, metanephric adenoma, or hemorrhagic cyst), 25\% will be an indolent tumor (papillary, chromophobe carcinoma) with limited metastatic potential, and $54 \%$ will be the more potentially malignant conventional clear-cell carcinoma that accounts for $90 \%$ of the metastatic renal tumors (Teloken et al., 2009; Algaba et al., 2011).

\section{END STAGE RENAL DISEASE: ASSOCIATION WITH CANCER AND KIDNEY CANCER}

A definite association between malignancy and ESRD has been reported (Matas et al., 1975; Cengiz, 2002). Stewart evaluated 28,855 patients who required renal replacement therapy and reported a fourfold increased incidence of cancer. Immune deficiency related cancers were increased from 1.5-fold while on dialysis to fivefold after transplantation and the initiation of antirejection medication. The authors speculated that this increase after transplantation could be virally mediated (Stewart et al., 2009). Liang matched 21,817 ESRD patients in Taiwan to patients from the general population without ESRD and found the risk of developing cancer was $64 \%$ higher in the ESRD patients (Liang et al., 2011). Lee evaluated 4582 patients with ESRD and found 106 patients that developed cancer. The most common cancers were from the GI tract (51\%), urinary tract (20\%), and lung (8\%). In this sub group of patients, $69 \%$ of the mortality was due to cancer (Lee et al., 2009). Mosconi et al. (2011) evaluated 1184 Italian patients with ESRD on a kidney transplant waiting list and found cancers in $2.2 \%$ of patients, most of which were non-metastatic with the most common arising from kidney and thyroid.

It has also been reported that ESRD patients have a higher prevalence of renal cell carcinoma than the general populations (Ishikawa and Kovacs, 1993) and distinct clinical and pathological features can be identified in ESRD patients. Neuzillet compared the pathological features of 303 renal cancer patients with ESRD to 947 sporadic renal cancer patients and found that the mean age at diagnosis was younger $(55 \mathrm{v} 62)$, the mean tumor size was smaller ( 3.7 vs. $7.3 \mathrm{~cm}$ ), more were asymptomatic ( 87 vs. $44 \%$ ), less were high stage (10 vs. $42 \%$ ), less had nodal metastasis ( 3 vs.
$12 \%)$ and less had distant metastasis (2 vs. 15\%). After a median follow up of 33 months, 13 ESRD (4.3\%) patients had died of renal cancer vs. $261(27.6 \%)$ from the sporadic tumor population. The authors concluded that RCC arising in the native kidneys of ESRD patients may have a more indolent natural history (Neuzillett et al., 2011). Hora described pathological characteristics of renal cortical tumors in 13 ESRD patients, which included 6 bilateral procedures, for a total of 19 kidney specimens. In 13 kidneys the tumors were multiple and in 6 solitary. Papillary and clear-cell tumors alone or in combination were reported (Hora et al., 2008). Hajj reported 89 nephrectomies (including 10 bilateral) resected in 79 patients with autosomal dominant polycystic disease (ADPKD), 50 of who had ESRD. In 11 of the 89 kidneys resected, renal cancer was found including 1 bilateral and 3 multifocal tumor. Of these, $58.3 \%$ were clear cell and $41.7 \%$ tubulopapillary carcinomas. The authors calculated that the prevalence of renal cancer in the combination of ADPKD and ESRD was two to three times more than in ESRD patients alone (Hajj et al., 2009).

Nouth reported a wide spectrum of tumor histology distinct from sporadic RCC in 34 ESRD patients that underwent RN for renal cancer. Pathologic sub types included acquired cystic disease (ACD) associated RCC, mucinous tubular, spindle cell, and Xp11.2 translocation renal cell carcinoma. In $9 / 15$ patients with a duration of dialysis less than 10 years, conventional clear cell was the predominant histology whereas ACD associated RCC was predominant (7/12) in those with dialysis of greater than 10 years (Nouth et al., 2009). Suson reported 15 post transplant patients who underwent nephrectomy for renal masses in their native kidney. A total of 22 renal units were removed and a total of 18 cancers, 10 of which were $\mathrm{P} 1$, were resected. There were 11 papillary, 4 clear cell, and 3 chromophobe cancers. Only one patient in this experience developed metastatic disease (Suson et al., 2011). These reports, when taken together, describe a propensity for the development of a wide range of renal cortical cancers in patients with ESRD whose renal tumors as a whole may have less metastatic potential than sporadic renal cancers.

\section{CHRONIC KIDNEY DISEASE: PREVALENT, SERIOUS, AND UNDERAPPRECIATED DISEASE}

Chronic kidney disease, defined as an estimated glomerular filtration rate (eGFR) of less than $60 \mathrm{ml} / \mathrm{min} / 1.73 \mathrm{~m}^{2}$, is increasingly viewed as a major public health problem in the United States and since 2003 is considered an independent cardiovascular risk factor (Kidney Disease Outcome Quality Initiative, 2002; Chobanian et al., 2003; Sarnak et al., 2003; Ritz and McClellan, 2004; Shlipak et al., 2005). The prevalence of CKD in the general population is $4 \%$ but may be as high as $30 \%$ in the elderly population. An estimated 19 million adults in the United States have CKD and by the year 2030, 2 million of these will progress to ESRD and be in need of chronic dialysis or renal transplantation (Coresh et al., 2007). Worldwide epidemics of cardiovascular disease, obesity, hypertension, and diabetes, all of which can have adverse effects on the kidney, have gained increasing attention but their contribution to the development of $\mathrm{CKD}$ has gone relatively unnoticed amongst clinicians and patients alike. The adverse impact of CKD on cardiovascular disease is significant as CKD progresses to ESRD (Stenvinkel, 2010). A study by Go involving 1,120,295 patients 
demonstrated a direct correlation between the stages of CKD and rates of hospitalization, cardiovascular events, and death, which occurred before overt ESRD requiring dialysis or renal transplantation (Go et al., 2004). As kidney function deteriorated, the percentage of patients with two associated cardiovascular risk factors increased from $34.7 \%$ (Stage 1 and 2 CKD) to $83.6 \%$ (for stage 3 ) to $100 \%$ for stage 4 and 5 subjects. Patients with CKD are more likely to require medical interventions to treat cardiovascular disease than those with normal renal function. The low prevalence of patients with Stage 4 or $5 \mathrm{CKD}$ is attributable to a 5 -year survival rate of only $30 \%$ (Foley et al., 2005).

The adverse impact of $\mathrm{CKD}$ increases as the patient population at risk ages. Stevens explored the prevalence and impact of CKD in patients over 65 in the USA in a large combined data set which included NHANES, KEEP, and a 5\% sample of Medicare ( $n=1,236,946)$ and found that as the eGFR decreased, the co morbid metabolic conditions of anemia, hypocalcemia, hyperphosphatemia, and hyperparathyroidism increased. The subsequent impact of these conditions on overall health has made CKD a critical disease in need of increased awareness by the entire medical community (Stevens et al., 2010). This high prevalence of CKD in the aging and elderly effects is superimposed upon the very same patient population most at risk for the development of cancer.

\section{CKD: ASSOCIATIONS WITH CANCER AND KIDNEY CANCER}

As with ESRD, there are now reports indicating that patients with CKD are at higher risk for the development of cancer in addition to cardiovascular disease. Weng evaluated 123,717 adults in Taiwan in 1998 and calculated their eGFR. After a median of over 7 years, mortality was ascertained by computer linkage to their national death registry. The investigators found a higher overall cancer mortality in CKD patients vs. non-CKD patients. CKD was associated with an adjusted hazard ratio of 1.74, 3.3, and 7.3 for liver, kidney, and urothelial cancers respectively (Weng et al., 2011). Wong evaluated 3654 patients in Australia aged 49-97 and followed them for a mean 10.1 years. Cancer developed in 711 patients (19.5\%). Men with CKD 3 were at increased risk for the development of cancer starting at an eGFR of 55 (HR 1.39). For every $10 \mathrm{ml} / \mathrm{min}$ decrement decline in eGFR, the risk of cancer rose $29 \%$ and was at greatest risk for an eGFR of 40 (HR 3.01) with lung and urinary tract the most likely diagnoses (Wong et al., 2009).

Cancer patients appear to have a higher rate of CKD than the general population. Launay-Vacker et al. (2007) evaluated 4684 patients with cancer, median age 58, and reported that 12 and $20 \%$ had an eGFR less than $60 \mathrm{ml} / \mathrm{min} / 1.73 \mathrm{~m}^{2}$ by the modification in diet and renal disease (MDRD) and Cockcroft Gault equations respectively. Canter reported the prevalence of baseline CKD in 1114 patients presenting with solid renal tumors. Twenty-two percent had stage 3 CKD or greater despite $88 \%$ having a serum creatinine within normal limits $(<1.4 \mathrm{mg} / \mathrm{dl})$. In a sub group of 282 patients 70 years or older, $113(40 \%)$ had CKD stage 3 (Huang et al., 2006). These results are similar to those first reported by MSKCC investigators which demonstrated a $26 \%$ rate of CKD in 662 patients with small renal tumors and a serum creatinine within normal limits (Huang et al., 2006).

\section{CANCER AND KIDNEY CANCER ASSOCIATED NEPHROPATHOLOGY}

The extent to which ESRD, CKD associated nephropathological changes are simply associated with kidney tumors or cause kidney tumors is not known and is of great current interest amongst urological oncologists, nephrologists, and pathologists alike. In patients with ESRD, numerous renal cysts develop and persistently grow in native kidneys even after transplantation. Goh reported 10 asymptomatic transplant recipients who developed renal cell carcinoma in native kidneys at a median of 5.8 years while their grafts were functioning at greater than $90 \%$ rate. The patients at greatest risk for developing renal cancer were those with preexisting renal cysts and those on dialysis the longest (Goh and Vathsala, 2011). In patients without ESRD/CKD and renal cancer, many nephropathological changes are observed. Bijol from Harvard Medical School examined the non-tumor bearing normal appearing kidney in 110 nephrectomy specimens resected for kidney cancer. Extensive and unsuspected underlying renal disease including vascular sclerosis, diabetic nephropathy, glomerular hypertrophy, mesangial expansion, and diffuse glomerulosclerosis was reported. Only $10 \%$ of patients had completely normal renal tissue adjacent to the tumor (Bijol et al., 2006). Henriksen et al. (2009) confirmed a wide range of kidney abnormalities in the non-neoplastic kidney, including mesangial sclerosis or hypercellularity, segmental sclerosis, crescent formation, glomerulitis, and glomerular basement membrane disease. Pathologists are now being urged to routinely report these findings in routine tumor nephrectomy specimens (Bonsib and Pei, 2010).

The precise mechanisms by which the uremic state, dialysis, and transplantation causes malignant transformation in the kidney are unknown and are likely multi-factorial. Cancer induced paraneoplastic nephropathy, exposure to toxins, viral mediated carcinogenesis, immune inhibition, and circulating toxins have all been implicated in the process of increased cancer in patients with ESRD/CKD (Stengel, 2010). Retention of uremic toxins, such as $p$-cresol, could promote malignant transformation by their inhibitory effect on the immune system and transendothelial leukocyte migration (Dou et al., 2002; Faure et al., 2006). Future research is required to define the precise mechanism by which uremic conditions predispose patients to cancer.

\section{RENAL TUMOR SURGERY AND NEW CONCERNS FOR CKD}

After World War 2, improvements in surgical technique and perioperative care allowed for the radical resection of massive renal tumors $(\mathrm{RN})$ with results indicating excellent local tumor control and long term survival in greater than $50 \%$ of patients in the absence of metastatic or regional nodal disease (Russo, 2006, 2011). However, a historic misconception was propagated that implied that the loss of a kidney to cancer surgery and the subsequent and expected rise in serum creatinine would have minimal if any impact of the patient's health as long as there was a normal contra lateral kidney. The renal transplant literature was cited as the clinical evidence to support this view since patients undergoing donor nephrectomy were reported not to have higher rates of kidney failure requiring dialysis or death (Segev et al., 2010). However, distinct differences between kidney donors and kidney tumor patients exist. Donors were carefully screened for medical 
co-morbidities and are generally young (age 45 or less; FehrmanEkholm et al., 2001; Goldfarb et al., 2001). In contrast, renal tumor patients are not screened, are older (mean age 61 years), and many have significant co-morbidities affecting baseline kidney function including metabolic syndrome, hypertension, coronary artery disease, obesity, vascular disease, and diabetes. In addition, as patient's age, particularly beyond 60 years, nephrons atrophy and glomerular filtration rate progressively decreases (Kaplan et al., 1975).

Evidence that $\mathrm{RN}$ could cause a significant rise in the serum creatinine when compared to $\mathrm{PN}$ in patients with renal cortical tumors of $4 \mathrm{~cm}$ or less was published by investigators from Mayo Clinic and MSKCC in 2000 and 2002, respectively. RN patients were more likely to have elevated serum creatinine levels to $>2.0 \mathrm{ng} / \mathrm{ml}$ and proteinuria (Mayo Study; Lau et al., 2000), a persistent finding even when study patients were carefully matched for associated risk factors (MSKCC study) including diabetes, smoking history, pre-operative serum creatinine, and ASA score (McKiernan et al., 2002). In both studies, oncological outcomes were highly favorable ( $>90 \%$ survival rates) whether PN or RN was performed. A new and emerging concern that the overzealous use of RN, particularly in elderly patients with small renal masses and common co-morbidities that can affect renal function, could be cause or worsen pre-existing CKD became a focus of intensive research. MSKCC investigators used a widely available formula, the MDRD equation (Stevens et al., 2006; http://www.nephron.com/MDRD_GFR.cgi), to eGFR in a retrospective cohort study of 662 patients with a normal serum creatinine and 2 healthy kidneys that underwent either elective PN or RN for a RCT $4 \mathrm{~cm}$ or less in diameter. To their surprise, 171 patients (26\%) had pre-existing CKD (GFR $<60)$. Data was analyzed using two threshold definitions of CKD, a GFR $<60 \mathrm{ml} / \mathrm{min} / 1.73 \mathrm{~m}^{2}$ or a GFR $<45 \mathrm{ml} / \mathrm{min} / 1.73 \mathrm{~m}^{2}$. After surgery, the 3-year probability of freedom from new onset of GFR $<60$ was $80 \%$ after PN but only $35 \%$ after RN. Corresponding values for 3 year probability of freedom from a GFR <45, a more severe level of CKD, was 95\% for PN and 64\% for RN. Multivariable analysis indicated that $\mathrm{RN}$ was an independent risk factor for the development of new onset CKD (Huang et al., 2006). Mayo Clinic investigators identified 648 patients from 1989 to 2003 treated with RN or PN for a solitary renal tumor less than or equal to $4 \mathrm{~cm}$ with a normal contra lateral kidney. In 327 patients younger than 65 it was found that $\mathrm{RN}$ was significantly associated with an increased risk of death which persisted after adjusting for year of surgery, diabetes, Charlson-Romano index, and tumor histology (Thompson et al., 2008).

Using the Surveillance, Epidemiology, and End Results cancer registry data linked with Medicare claims, MSKCC investigators studied 2991 patients older than 65 years for resected renal tumors of $4 \mathrm{~cm}$ or less from 1995 to 2002 . A total of 254 patients (81\%) underwent RN and 556 patients underwent PN. During a median follow up of 4 years, 609 patients experienced a cardiovascular event and 892 patients died. After adjusting for pre-operative demographic and co-morbidity variables, $\mathrm{RN}$ was associated with a 1.38 times increased risk of overall mortality and a 1.4 times greater number of cardiovascular events (Huang et al., 2009). Similar results were reported in patients undergoing laparoscopic RN and PN (Foyil et al., 2008). Because of these reports, urologists are now increasingly aware that CKD can be caused or pre-existing CKD significantly worsened by the liberal use of $\mathrm{RN}$ for the treatment of the small renal mass (Lane et al., 2009). Short term end points, including length of hospital stay, analgesic requirements, and cosmetic elements viewed by many as the reason to elect laparoscopic RN, must now be tempered by the guaranteed renal functional decline after RN. The most recent AUA guidelines for the management of the small renal tumor emphasize these points and strongly support the use of PN whenever technically feasible (Campbell et al., 2009).

\section{RADICAL NEPHRECTOMY IS OVER-UTILIZED}

Despite the above well described oncological and medical arguments in the contemporary literature supporting PN as the ideal treatment for small renal masses, the urological oncology community continues to use $\mathrm{RN}$ as the predominant treatment of the small renal mass. A cross sectional view of clinical practice using the Nationwide Inpatient Sample, revealed that only 7.5\% of kidney tumor operations in the United States 1988-2002 were PN (Hollenback et al., 2006). Using the surveillance epidemiology and end results (SEER) data base, investigators from the University of Michigan reported that only $20 \%$ of all renal cortical tumors between 2 and $4 \mathrm{~cm}$ were treated by PN (Miller et al., 2006a). Using the SEER data base linked to Medicare claims, MSKCC investigators reported a PN utilization rate of only $19 \%$ for T1a tumors (4 cm or less; Huang et al., 2009). Interestingly and for uncertain reasons, women and elderly patients are more likely to be treated with RN (Dulabon et al., 2010). Many urologists believe a "quick" RN in an elderly patient would expose the patient to fewer post operative complications than would a PN. However, MSKCC investigators evaluated age and type of procedure performed in 1712 patients with kidney tumors found a lack of statistical evidence that the risk of complications associated with PN increased with advancing age. Furthermore, no evidence was reported linking age to estimated blood loss or operative time. Given the advantages of renal functional preservation, the authors concluded that elderly patients should be perfectly eligible for PN (Lowrance et al., 2010). As mentioned above, the elderly patients have the highest rates of underlying CKD and are most vulnerable to the adverse impact of RN.

Although the urology literature has a great many articles written concerning the use of laparoscopic techniques to resect kidney tumors, the penetrance of laparoscopic $\mathrm{RN}$ according to the National Inpatient Sample from 1991 to 2003 was only 4.6\% with a peak incidence of $16 \%$ in 2003 . This data indicates that the bulk of "kidney wasting operations" are being done by traditional open surgical approaches (Miller et al., 2006b). In England, a similar under-utilization of PN was reported in 2002 with only 108 (4\%) PN out of 2671 nephrectomies performed (Nuttail et al., 2005). Investigators at MSKCC tracked nephrectomy use in 1533 patients between 2000 and 2007 excluding patients with bilateral tumors and tumors in a solitary kidney and including only patients with an eGFR of greater than $45 \mathrm{ml} / \mathrm{min} / 1.73 \mathrm{~m}^{2}$. Overall $854(56 \%)$ patients underwent PN and 679 (44\%) underwent RN. In the 820 patients with a renal tumor of $4 \mathrm{~cm}$ or less, the frequency of PN increased from $69 \%$ in 2000 to $89 \%$ in 2007. In the 365 patients 
with a renal tumor from 4 to $7 \mathrm{~cm}$, the frequency of PN increased from $20 \%$ in 2000 to $60 \%$ in 2007 . Despite a commitment to kidney sparing operations during this time frame by the MSKCC group, multivariate analysis indicated that $\mathrm{PN}$ was a significantly favored approach for males, younger patients, smaller tumors, and open surgeons (Thompson et al., 2009).

\section{CONCLUSION}

A previously understood association between ESRD patient's native kidneys and the development of kidney cancer has been extended now to include patients with CKD. CKD is an increasing public health problem in the United States and now considered an independent risk factor for the development of cardiovascular morbidity and mortality. CKD is multi-factorial and may be due to common medical conditions including hypertension, diabetes, obesity and vascular disease. As the eGFR decreases, metabolic complications increase with patients over the age of 65 years particularly susceptible. These aging patients also have the greatest vulnerability to the development of cancer. Patients with cancer in general and kidney cancer in particular may have concomitant

\section{REFERENCES}

Algaba, F., Akaza, H., López-Beltrán, A., Martignoni, G., Moch, H., Montironi, R., and Reuter, V. (2011). Current pathology keys of renal cell carcinoma. Eur. Urol. 60, 634-643.

Bijol, V., Mendez, G. P., Hurwitz, S., Rennke, H. G., and Nosé, V. (2006). Evaluation of the nonneoplastic pathology in tumor nephrectomy specimens: predicting the risk of progressive renal failure. Am. J. Surg. Pathol. 30, 575.

Birkelan, S. A., Lokkegaard, H., and Storm, H. H. (2000). Cancer risk in patients on dialysis and after renal transplantation. Lancet 355, 1886-1887.

Bonsib, S. M., and Pei, Y. (2010). The non-neoplastic kidney in tumor nephrectomy specimens: what can it show and what is important? $A d v$. Anat. Pathol. 4, 235-250.

Buell, J. F., Gross, T. G., and Woodle, E. S. (2005). Malignancy after transplantation. Transplantation 80 , S254-S264.

Campbell, S. C., Novick, A. C., Belldegrun, A., Blute, M. L., Chow, G. K., Derweesh, I. H., Faraday, M. M., Kaouk, J. H., Leveille, R. J., Matin, S. F., Russo, P., and Uzzo, R. G. (2009). Guideline for management of the clinical T1 renal mass. J. Urol. 182, 1271-1279.

Cengiz, K. (2002). Increased incidence of neoplasia in chronic renal failure $(20$ year experience). Int. Urol. Nephrol. 33, 121-126.

Chobanian, A. V., Bakris, G. L., Black, H. R., Green, L. A., Izzo,
J. L., Jones, D. W., Materson, B. J., Oparil, S., Wright, J. T., Roccella, E. J., and the National High Blood Pressure Education Program Coordinating Committee. (2003). The Seventh Report of the Joint National Committee on TN prevention, detection, evaluation, and treatment of high blood pressure: the JNC 7 report. JAMA 289, 2560-2572.

Coresh, J., Selvin, E., Stevens, L. A., Manzi, J., Kusek, J. W., Eggers, P., Van Lente, F., and Levey, A. S. (2007). Prevalence of chronic kidney disease in the United States. JAMA 298, 2038-2047.

Dou, L., Cerini, C., Brunet, P., Guillanelli, C., Moal, V., Grau, G., De Smet, R., Vanholder, R., Sampol, J., and Berland, Y. (2002). Pcresol, a uremic toxin, decreases endothelial cell response to inflammatory cytokines. Kidney Int. 62, 1999-2009.

Dulabon, L. M., Lowrance, W. T., Russo, P., and Huang, W. C. (2010). Trends in renal tumor surgery delivery within the United States. Cancer 116, 2316-2321.

Faure, V., Cerini, C., Paul, P., Berland, Y., Dignat-George, F., and Brunet, P. (2006). The uremic solute p-cresol decreases leukocyte transendothelial migration in vitro. Int. Immunol. 10, 1453-1459.

Fehrman-Ekholm, I., Duner, F., Brink, B., Tydén, G., and Elinder, C. G. (2001). No evidence of accelerated loss of kidney function in living kidtional follow up. Transplantation 72, 444-449. ney donors: results from a cross sec-

CKD rates as high as $40 \%$. In the non-neoplastic kidney at the time of nephrectomy, extensive nephropathological findings are observed in the vast majority of patients. It is not clear if these changes are a direct cause of renal neoplasia or a result of medical co-morbidities that are prevalent in the kidney tumor patients. The precise mechanism by which the uremic state causes malignant transformation is not known but it is speculated that uremic toxins, viral mediators, and immune inhibition could play a role in the increased rate of kidney cancer seen in ESRD/CKD patients. For surgeons operating on small renal tumors, it is now clear that PN provides equivalent oncological results to $\mathrm{RN}$ while at the same time maximally preserving renal function and preventing or delaying the onset of CKD and its late cardiovascular morbidity and mortality. Despite a decade of clinical evidence in support of kidney preservation surgical techniques, $\mathrm{RN}$ remains overused in the United States and abroad. Formal support for PN in the management of small renal masses has been made by major urological surgical organizations. A working knowledge of the bi directional relationship of CKD/ESRD and the surgical management of renal tumors is now essential for all urological oncologists.

Foley, R. N., Wang, C., and Collins, A. J. (2005). Cardiovascular risk factor profiles and kidney function stage in the US general population: the NHANES 3 study. Mayo Clin. Proc. 80, 1270-1277.

Foyil, K. V., Ames, C. D., Ferguson, Weld, K. J., Figenshau, R. S., Venkatesh, R., Yan, Y., Clayman, R. V., and Landman, J. (2008). Long-term changes in creatinine clearance after laparoscopic renal surgery. J. Am. Coll. Surg. 206, 511-515.

Go, A. S., Chertow, G. M., Fan, D., McCulloch, C. E., and Hsu, C. Y. (2004). Chronic kidney disease and the risks of death, cardiovascular events, and hospitalization. N. Eng. J. Med. 351, 1296.

Goh, A., and Vathsala, A. (2011) Re: native renal cysts and dialysis duration are risk factors for renal cell carcinoma in renal transplant recipients. Am. J. Transplant. 11, 86-92.

Goldfarb, D. A., Matin, S. F., Braun, W. E., Schreiber, M. J., Mastroianni, B., Papajcik, D., Rolin, H. A., Flechner, S., Goormastic, M., and Novick, A. C. (2001). Renal outcome 25 years after donor nephrectomy. J. Urol. 166, 2043.

Hajj, P., Ferlicot, S., Massoud, W., Awad, A., Hammoudi, Y., Carpentier, B., Durrbach, A., Droupy, S., and Benoit, G. (2009). Prevalence of renal cell carcinoma in patients with autosomal dominant polycystic kidney disease and chronic renal failure. Urology 74, 631-634.

Henriksen, K. J., Meehan, S. M., and Chang, A. (2009). Nonneoplastic kidney diseases in adult tumor nephrectomy and nephroureterectomy specimens: common, harmful, yet underappreciated. Arch. Pathol. Lab. Med. 133, 1012-1025.

Hollenback, B. K., Tash, D. A., Miller, D. C., Dunn, R. L., and Wei, J. T. (2006). National utilization trends of partial nephrectomy for renal cell carcinoma: a case of underutilization? Urology 67, 254-259.

Hora, M., Hes, O., Reischig, T., Urge, T., Klecka, J., Ferda, J., Michal, M., and Eret, V. (2008). Tumors in endstage kidney. Transplant. Proc. 10, 3354-3358.

Huang, W. C., Elkin, E. B., Levey, A. S., Jang, T. L., and Russo, P. (2009). Partial nephrectomy versus radical nephrectomy in patients with small renal tumors-is there a difference in mortality and cardiovascular outcomes. J. Urol. 181, 55-62.

Huang, W. C., Levey, A. S., Serio, A. M., Snyder, M., Vickers, A. J., Raj, G. V., Scardino, P. T., and Russo, P. (2006). Chronic kidney disease after nephrectomy in patients with renal cortical tumors: a retrospective cohort study. Lancet Oncol. 7, 735-740.

Ishikawa, I., and Kovacs, G. (1993). High incidence of papillary renal cell tumors in patients on chronic haemodialysis. Histopathology 22, 135-139.

Kaplan, C., Pasternack, B., Shah, H., and Gallo, G. (1975). Age-related incidence of sclerotic glomeruli in human kidneys. Am. J. Pathol. 80, 227. 
Kattan, M. W., Reuter, V., Motzer, R. J., Katz, J., and Russo, P. (2001). A postoperative prognostic nomogram for renal cell. J. Urol. 166, 63-67.

Kidney Disease Outcome Quality Initiative. (2002). K/DOQI clinical guideline for chronic kidney disease evaluation, classification, stratification. Am. J. Kidney Dis. 39 (Suppl. 2), 51:5246.

Lane, B. R., Poggio, E. D., Herts, B. R., Novick, A. C., and Campbell, S. C. (2009). Renal function assessment in the era of chronic kidney disease: renewed emphasis on renal function centered patient care. J. Urol. 182, 436-444.

Lau, W. K., Blute, M. L., Weaver, A. L., Torres, V. E., and Zincke, H. (2000). Matched comparison of radical nephrectomy vs. nephron-sparing surgery in patients with unilateral renal cell carcinoma and a normal contra lateral kidney. Mayo Clin. Proc. 75, 1236-1242.

Launay-Vacker, V., Oudard, S., Janus, N., Gligorov, J., Pourrat, X., Rixe, O., Morere, J. F., Beuzeboc, P., Deray, G., and Renal Insufficiency and Cancer Medications (IRMA) Study Group. (2007). Prevalence of renal insufficiency in cancer patients and implications for anti cancer drug management. The renal insufficiency and anticancer medications study (IRMA). Cancer 110, 1376-1384.

Lee, J. E., Han, S. H., Cho, B. C., Park, J. T., Yoo, T. H., Kim, B. S., Park, H. C., Kang, S. W., Lee, H. Y., Han, D. S., Ha, S. K., and Choi, K. H. (2009). Cancer in patients on chronic dialysis. J. Korean Med. Sci. 24 (Suppl. 1), S95-S101.

Liang, J. A., Sun, L. M., Yeh, J. J., Sung, F. C., Chang, S. N., and Kao, C. H. (2011). The association between malignancy and end stage renal disease in Taiwan. Jpn. J. Clin. Oncol. 41, 752-757.

Lipworth, L., McLaughlin, J. K., Tarone, R. E., and Blot, W. J. (2011). Renal cancer paradox: higher incidence but not higher mortality among AfricanAmericans. Eur. J. Cancer Prev. 20, 331-333.

Ljungberg, B., Campbell, S. C., Cho, H. Y., Jacqmin, D., Lee, J. E., Weikert, S., and Kiemeney, L. A. (2011). The epidemiology of renal cell carcinoma. Eur. Urol. 60, 615-621.

Lowrance, W. T., Yee, D. S., Savage, C., Cronin, A. M., O'Brien, M. F., Donat, M., Vickers, A., and Russo, P. (2010). Complications after radical and partial nephrectomy as a function of age. J. Urol. 183, 1725-1730.

Mandayam, S., and Shahinian, V. B. (2008). Are chronic dialysis patients at increased risk for cancer? $J$. Nephrol. 21, 166-174.

Matas, A. J., Simmons, R. L., Kjellstrand, C. M., Buselmeier, T. J., and Naajarian, J. S. (1975). Increased incidence of malignancy during chronic renal failure. Lancet 1, 883-886.

McKiernan, J., Simmons, R., Katz, J., and Russo, P. (2002). Natural history of chronic renal insufficiency after partial and radical nephrectomy. Urology 59, 816-820.

McLaughlin, J. K., and Lipworth, L. (2000). Epidemiologic aspects of renal cell cancer. Semin. Oncol. 27, 115-123.

Miller, D. C., Hollingsworth, J. M., Hafez, K. S., Daignault, S., and Hollenbeck, B. K. (2006a). Partial nephrectomy for small renal masses. An emerging quality of care concern? J. Urol. 175, 853-857.

Miller, D. C., Taub, D. A., Dunn, R. L., Wei, J. T., and Hollenbeck, B. K. (2006b). Laparoscopy for renal cell carcinoma: diffusion versus regionalization? J. Urol. 176, 1102-1106.

Mosconi, G., Stalterii, L., Centofanti, F., Capelli, I., Carretta, E., Persici, E., Ubaldi, G., Battaglino, G., Raimondi, C., Scolari, M. P., and Stefoni, S. (2011). Incidence o cancer in kidney transplantation waiting list patients: a single center experience. Transplant. Proc. 43, 1003-1005.

Neuzillett, Y., Mathieu, R., Long, J. A., Gigante, M., Paparel, P., Poissonnier, L., Baumert, H., Escudier, B., Lang, H., Rioux-Leclercq, N., Bigot, P., Bernhard, J. C., Albiges, L., Bastien, L., Petit, J., Saint, F., Bruyere, F., Boutin, J. M., Brichart, N., Karam, G., Branchereau, J., Ferriere, J. M., Wallerand, H., Barbet, S., Elkentaoui, H., Hubert, J., Feuillu, B., Theveniaud, P. E., Villers, A., Zini, L., Descazeaux, A., Roupret, M., Barrou, B., Fehri, K., Lebret, T., Tostain, J., Terrier, J. E., Terrier, N., Martin, L., Dugardin, F., Galliot, I., Staerman, F., Azemar, M. D., Irani, J., Tisserand, B., Timsit, M. O., Sallusto, F., Rischmann, P., Guy, L., Valeri, A., Deruelle, C., Azzouzi, A. R., Chautard, D., Mejean, A., Salomon, L., Rigaud, J., Pfister, C., Soulié, M., Kleinclauss, F., Badet, L., Patard, J. J., Comité de Transplantation de l'Association Française d'Urologie, and Comité de Cancérologie de l'Association Française d'Urologie. (2011). Renal cell carcinoma (RCC) in patients with end stage renal disease exhibits many favourable clinical, pathologic, and outcome features compared with RCC in the general population. Eur. Urol. 60, 366-373.

Nouth, M. A., Kuroda, N., Yamashita, M., Hayashida, Y., Yano, T., Minakuchi, J., Taniguchi, S. Nomura, I., Inui, M., Sugimoto, M., and Kakehi, Y. (2009). Renal cell carcinoma in patients with end stage renal disease: relationship between histological type and duration of dialysis. BJU Int. 105, 620-627.

Nuttail, M., Cathcart, van der Meulen, J. Gillatt, D., McIntosh, G., and Emberton, M. (2005). A description of radical nephrectomy practice and outcomes in England: 1995-2002. BJU Int. 96, 58-61.

Ritz, E., and McClellan, W. W. (2004). Overview: increased cardiovascular risk in patients with minor renal dysfunction: an emerging issue with farreaching consequences. J. Am. Soc. Nephrol. 15, 513-516.

Russo, P. (2000). Renal cell carcinoma: presentation, staging, and surgical treatment. Semin. Oncol. 27, 160-176.

Russo, P. (2006). “Open radical nephrectomy for localized renal cell carcinoma," in Genitourinary Oncology, 3rd Edn, ed. N. J. Vogelzang (Philadelphia: Lippincott Williams and Wilkins), 725-731.

Russo, P. (2010). Partial nephrectomy for renal cancer (I). BJU Int. 105, 1206-1220.

Russo, P. (2011). The role of surgery in the management of early-stage renal cancer. Hematol. Oncol. Clin. North Am. 25, 737-752.

Russo, P., Jang, T., Eggener, S., Pettus, J., Karellas, M., and O'Brien, F. (2008). Survival rates after resection for localized kidney cancer 19892004. Cancer 113, 84-96.

Sarnak, M., Levey, A. S., Schoolwerth, A. C., Coresh, J., Culleton, B., Hamm, L. L., McCullough, P. A., Kasiske, B. L., Kelepouris, E., Klag, M. J., Parfrey, P., Pfeffer, M., Raij, L., Spinosa, D. J., and Wilson, P. W. (2003). Kidney disease as a risk factor for the development of cardiovascular disease: a statement from the American Heart Association Council on Kidney in Cardiovascular Disease. High blood pressure research, clinical cardiology, and epidemiology and prevention. Circulation 108, 2154-2169.

Segev, D. L., Muzaale, A. D., Caffo, B. S., Mehta, S. H., Singer, A. L., Taranto, S. E., McBride, M. A., and Montgomery, R. A. (2010). Perioperative mortality and long-term survival following live kidney donation. JAMA 503, 959-966.

Shlipak, M. G., Fried, L. F., Cushman, M., Manolio, T. A., Peterson, D. Stehman-Breen, C., Bleyer, A., Newman, A., Siscovick, D., and Psaty, B. (2005). Cardiovascular mortality risk in chronic kidney disease: comparison of traditional and novel risk factors. JAMA 293, 1737-1745.

Stengel, B. (2010). Chronic kidney disease and cancer: a troubling connection. J. Nephrol. 23, 253-262.

Stenvinkel, P. (2010). Chronic kidney disease: a public health priority and harbinger of premature cardiovascular disease. J. Int. Med. 268, 456-467.

Stevens, L. A., Coresh, J., Green, T., and Levey, A. S. (2006). Assessing kidney function - measured and estimated glomerular filtration rate. N. Engl. J. Med. 354, 2473-2483.

Stevens, L. A., Li, S., Wang, C., Becker, B. N., Bomback, A. S., Brown, W. W., Burrows, N. R., Jurkovitz, C. T., McFarlane, S. I., Norris, K. C., Shilpak, M., Whaley-Cornell, A. T., Chen, S. C., Barkis, G. L., and McCullough, P. A. (2010). Prevalence of CKD and co morbid illness in elderly patients in the United State: results from the Kidney Early Evaluation Program (KEEP). Am. J. Kidney Dis. 55 (3 Suppl. 2), S23-S33.

Stewart, J. H., Vajdoc, C. M., van Leeuwen, M. T., Amin, J., Webster, A. C., Chapman, J. R., McDonald, S. P., Grulich, A. E., and McCredie, M. R. (2009). The pattern of excess cancer in dialysis and transplantation. Nephrol. Dial. Transplant. 10, 3225-3231.

Suson, K. D., Sausville, J. E., Sener, A., and Phelan, M. W. (2011) Native nephrectomy for renal cell carcinoma in transplant recipients. Transplantation 91, 1376-1379.

Teloken, P. E., Thompson, R. H., Tickoo, S. K., Cronin, A., Savage, C., Reuter, V. E., and Russo, P. (2009). Prognostic impact of histological subtype in patients with surgically treated localized renal cell carcinoma. J. Urol. 182, 2132-2136.

Thompson, H. R., Boorjian, S. A., Lohse, C. M., Leibovich, B. C., Kwon, E. D., Cheville, J. C., and Blute, M. L. (2008). Radical nephrectomy for pTla renal masses may be associated with decreased overall survival compared to partial nephrectomy. J. Urol. $179,468-473$.

Thompson, H. R., Kaag, M., Vickers, a., Kundu, S., Bernstein, M., Lowrance, W., Galvin, D., Dalbagni, G., Touijer, K., and Russo, P. 
(2009). Contemporary use of partial nephrectomy nephrectomy at a tertiary care center in the United States. J. Urol. 181, 993-997.

Weng, P. H., Hung, K. Y., Huang, H. L., Chen, J. H., Sung, P. K., and Huang, K. C. (2011). Cancer specific mortality in chronic kidney disease: longitudinal follow up of a large cohort. Clin. J. Am. Soc. Nephrol. 6, 1121-1128.
Wong, G., Hayen, A., Chapman, J. R., Webster, A. C., Want, J. J., Mitchell, P., and Craig, J. C. (2009). Association of CKD and cancer risk in older people. J. Am. Soc. Nephrol. 20, 1341-1350.

Conflict of Interest Statement: The author declares that the research was conducted in the absence of any commercial or financial relationships that could be construed as a potential conflict of interest.

Received: 04 February 2012; paper pending published: 28 February 2012; accepted: 10 March 2012; published online: 02 April 2012.

Citation: Russo P (2012) End stage and chronic kidney disease: associations with renal cancer. Front. Oncol. 2:28. doi: 10.3389/fonc.2012.00028
This article was submitted to Frontiers in Genitourinary Oncology, a specialty of Frontiers in Oncology.

Copyright (c) 2012 Russo. This is an open-access article distributed under the terms of the Creative Commons Attribution Non Commercial License, which permits non-commercial use, distribution, and reproduction in other forums, provided the original authors and source are credited. 